\title{
Molecular T cell biology - basic and translational challenges in the twenty-first century
}

\author{
Ellis L. Reinherz ${ }^{1,2,3 *}$ and Oreste Acuto ${ }^{4}$ \\ - Laboratory of Immunobiology, Dana Farber Cancer Institute, Boston, MA, USA \\ 2 Department of Medicine, Harvard Medical School, Boston, MA, USA \\ 3 Harvard Faculty of Arts and Sciences, Harvard University, Cambridge, MA, USA \\ 4 T Cell Signalling Laboratory, Department of Pathology, Sir William Dunn School of Pathology, University of Oxford, Oxford, UK \\ *Correspondence: ellis_reinherz@dfci.harvard.edu; oreste.acuto@path.ox.ac.uk
}

\section{THE BEGINNING OF MOLECULAR T CELL BIOLOGY}

The field of immunology has been grounded in basic biology since its inception, with myriad applications to human disease. Development of both preventive and therapeutic vaccines as treatments for human infectious diseases dates to the time of Pasteur's efforts in the nineteenth century (Debre and Forster, 1998). Since then, harnessing immunity through precise knowledge of molecular and cellular mechanisms was perceived as important in medical science.

Adaptive immunity is the most sophisticated and effective system to combat and rid infectious pathogens (Murphy et al., 2007). Adaptive immunity endows jawed vertebrates, including mammals, with precursors of $\mathrm{T}$ (thymus-derived), and $\mathrm{B}$ (bone marrow-derived) lymphocytes able to generate a repertoire of clonotypic antigen receptors (TCR and BCR) of immense diversity from somatic rearrangements of variable gene segments (VDJ recombination). Spatio-temporally controlled differentiation and selection processes of those cells shape two complementary "arms" of the immune system, offering protection with exquisite specificity, sensitivity, and long-term memory.

Key discoveries during the last quarter of the twentieth century began to unravel the cellular and molecular nature of adaptive immunity. In the 1960s, T and B lymphocytes were identified and their interactions shown to be essential for antibody production. The basic paradigm of immunoglobulin (Ig) gene rearrangements that generate antibody diversity was revealed in 1976 (Tonegawa, 1993). The "dual" specificity of $\mathrm{T}$ cells for foreign peptide and selfMHC inferred by functional studies was discovered and clearly noted to be distinct from the "single" specificity of antibody recognition of foreign proteins (Zinkernagel, 1997). This realization then led to an intense effort to understand the molecular puzzle represented by the self versus non-self recognition and the receptor and ancillary molecules on $\mathrm{T}$ cells responsible for this unusual recognition.

Initial studies suggesting the existence of an "I-J-specific" suppressor factor secreted by $\mathrm{T}$ cells and TCR specificity achieved through Ig genes were refuted. Rather, the discovery of how to expand $\mathrm{T}$ cells in vitro, via IL-2 dependent $\mathrm{T}$ cell cloning (Baker et al., 1979), in conjunction with monoclonal antibody (Milstein, 1993), and flow cytometry screening (Julius et al., 1972) technologies together with in vitro functional analyses were decisive in molecular identification for the long sought-after TCR. The key breakthroughs came in the early 1980 s with the identification in human of a clonotypic disulfide-linked heterodimer, the $\alpha \beta$ Ti, which together with $\mathrm{CD} 3$ molecules, were essential for antigen/MHC recognition and cellular activation (Reinherz et al., 1982; Acuto et al., 1983a; Meuer et al., 1983a,b). Biochemical evidence showed that, similar to Ig molecules, both Ti $\alpha$ and $\beta$ chains possessed variable and constant regions (Acuto et al., 1983a,b). A comparable $\alpha \beta$ Ti was soon identified also in the mouse in 1983 , with similar cognate immune recognition features (Haskins et al., 1983; Kappler et al., 1983). Those murine studies supported an earlier suggestion that a tumor-specific marker on mouse T-lymphoma cells might be TCR-related (Allison et al., 1982). Within 2 years, cDNAs for TCR $\alpha \beta$ subunits were obtained by several groups including Davis and Mak with the bona-fide identification established by the Ti $\alpha \beta$ protein sequence (Acuto et al., 1984; Hedrick et al., 1984a,b; Yanagi et al., 1984). Collectively, these results confirmed the clonotypic nature of the Ti $\alpha \beta$ first identified biochemically. These studies showed that TCR combinatorial diversity was generated by the same type of site-specific gene recombination mechanisms as with Ig genes, but without somatic hypermutation and led to identification of a second type of TCR, the $\gamma \delta$ TCR (reviewed in Tonegawa, 1993).

CD4 and CD8 co-receptors identified during the same period, were soon recognized as ancillary structures that optimize TCR recognition and $\mathrm{T}$ cell activation via interaction with monomorphic segments of MHC class II and I molecules, respectively (Meuer et al., 1982). A few years later, the "dual recognition" puzzle was solved when it was shown that MHC class I and class II proteins bound foreign and self-peptides derived from degradation of intracellular or exogenous proteins and that such complexes could be recognized by the TCR (reviewed in Unanue, 2006). Structures of peptides complexed with MHC molecules then followed (Bjorkman et al., 1987; Jardetzky et al., 1994).

\section{T CELL ACTIVATION AND REGULATION}

TCR signaling evokes T cell lineage commitment and repertoire selection during development, maintains the peripheral $\mathrm{T}$ cell pool, and further differentiates naïve $\mathrm{T}$ cells into effector or memory cell populations upon immune stimulation. Through many studies, we know that the TCR is a multimeric transmembrane complex composed of an antigen binding clonotypic heterodimer $(\alpha \beta$ or $\gamma \delta)$ in non-covalent association with the signal-transducing

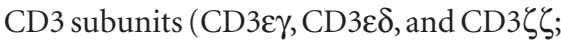
Clevers et al., 1988). Structural analyses of TCR or CD4 and CD8 co-receptors alone or in complex with pMHC using X-ray crystallography and NMR in conjunction 
with biophysical studies have contributed to our understanding of cognate recognition (Wang and Reinherz, 2002; Rudolph et al., 2006). Structures of CD3E $\gamma$ and CD $3 \varepsilon \delta$ ectodomain heterodimers (Sun et al., 2001; Arnett et al., 2004; Kjer-Nielsen et al., 2004; Sun et al., 2004) and of transmembrane CD3 $\zeta \zeta$ homodimers (Call et al., 2006) have provided clues as to their unique dimerization interfaces and topology relative to the $\alpha \beta$ dimer, which should be relevant to understand how the TCR transduces signals. Upon interaction with $\mathrm{pMHC}$, the $\alpha \beta$ TCR heterodimer induces phosphorylation of immunoreceptor tyrosine-based activation motifs (ITAMs) in the cytoplasmic tails of the associated CD3 subunits (Reth, 1989; Irving and Weiss, 1991; Letourneur and Klausner, 1992). Recent evidence suggests that TCR complex quaternary changes by means of torque exerted during recognition of pMHC on the opposite face of an antigen presenting cell could be the initial trigger (Kim et al., 2009). However, this signal transduction mechanism appears rather unconventional in that the TCR and the tyrosine kinase Lck required to initiate signaling are not constitutively associated, instead interacting only after TCR engagement. In addition, a relatively large fraction of Lck is constitutively activated (Nika et al., 2010), suggesting that TCR and kinase colocalization is the relevant event to induce rapid and sensitive signal transduction. This scenario poses a challenge requiring a deep understanding of the biophysics of protein dynamics in biological membranes. Likewise, clarification of the basic physical and chemical events that convert a recognition of pMHC by a weakly interacting $\left(\sim 1-100 \mu \mathrm{M} \mathrm{K}_{\mathrm{d}}\right)$ TCR into an intracellular signal with great specificity, sensitivity, and diverse biological outcomes remains an intense challenge for future investigation.

In vivo, chemokines function as chemoattractants to guide cell migration, including movements of $\mathrm{T}$ cells via interaction with the chemokine receptors, $G$ protein-coupled receptors on the surface of leukocytes (Fernandez and Lolis, 2002). Their ligation promotes signal cascades including changes in avidity and cell adhesion via integrins. TCR stimulation also modulates integrin avidity on T cells (Hynes, 2002). It can be anticipated that these areas will continue to be intensely investigated for at least two reasons: (1) understanding in vivo activation of the adaptive response; and (2) exploiting this knowledge for modulating these mechanisms as additional tools to fend off autoimmunity and improve vaccination.

\section{FROM "BLACK BOX" TO "PANDORA'S BOX": DYNAMIC SIGNALOSOMES, IMMUNOLOGICAL SYNAPSE, AND COMPUTATIONAL MODELING}

Since the mid 1980s, many groups engaged in comprehending the role of TCR, coreceptors, co-stimulatory, and cytokine receptors in $\mathrm{T}$ cell activation. $\mathrm{T}$ cells were mysterious "black boxes" in which an input (e.g., signal one, signal two, cytokines) may result in diverse outputs (development, effector cell differentiation, lethal hit, cell death), with few clues as to how these processes develop biochemically. Work from the early 1990s until the present has brought to light most of the $\mathrm{T}$ cell signaling tool-box elements, now confronting $\mathrm{T}$ cell biologists with the opening of "Pandora's box." The interesting surprise has been that highly specific or unique sets of signaling proteins are grafted onto a template of prototypic signaling schemes and components found in virtually all cell types. This feature is discernible from the TCR and ancillary receptors down to the control of gene expression (Weiss, 2009) and likely serves distinctive developmental, survival, and cell activation processes associated with the $\mathrm{T}$ cell arm of the immune response. The most recent discovery is of a T cell unique signalosome component important in $\mathrm{T}$ cell positive selection (Fu et al., 2009; Johnson et al., 2009; Lesourne et al., 2009) suggested to regulate the Ras pathway (Brockmeyer et al., 2010). Not unexpectedly, such a vital TCR-based signaling machinery is counter-balanced by negative regulators of activation. Both immunologic (CTLA-4/CD80 or 86,PD-1R/ PD-1) and more general (Adenosine receptor A2A-R/adenosine) inhibitory checkpoint pathways have been revealed. These immunosuppressive pathways prevent collateral damage from inflammation leading to termination of immune cell activation in intimate associate with regulatory $\mathrm{T}$ cells (Rudd et al., 2009; Sitkovsky, 2009). Control mechanisms establishing positive and negative feedback with their tunable thresholds have been brought to light in TCR signaling (Acuto et al., 2008). Combinations of quantitative data and computational modeling of such events are just beginning to provide us with the basic rules that shape the unique biology of the "system" T cell. This should help to explain how transient events of phosphorylation and other protein modification allow $\mathrm{T}$ cells to coordinately switch on and off functional pathways by integrating signals in time and space from multiple receptors, thereby controlling gene expression, morphological changes, and mobility. We can anticipate that deep insights in this area will be revealed by determining the dynamics of the global proteome of different $\mathrm{T}$ cell subsets, during distinct differentiation stages and following one or more stimuli. The era of this bold challenge has already begun with enormous technological progress complementing sophisticated transcriptome and metabolome approaches (Luber et al., 2009; Mayya et al., 2009; Brockmeyer et al., 2010).

Of great interest has been the discovery that, upon pMHC stimulation, the T cell/ APC interface forms micrometer-scale TCR clusters arising from smaller ones creating what is referred to as the Immunological Synapse (Dustin et al., 2010). These molecular platforms, connected to underlying signalosomes through organization of dynamic protein complexes, likely provide signaling stability as well as signaling complex disposal/recycling. Thus, the IS ensures prolonged signaling and orchestrates expression of $\mathrm{T}$ cell differentiation programs and consequently cell fates. Increasingly sophisticated technologies of super-resolution optical microscopy and other biophysical approaches in live cells will add further understanding of the spatial organization of the cellular chemistry.

\section{AMALGAMATION OF BASIC AND TRANSLATIONAL SCIENCES}

Translational endeavors aim to block $\mathrm{T}$ cell activation in the setting of organ transplantation or autoimmunity or, conversely, stimulate $\mathrm{T}$ cell activation to foster immunity to protect against infectious diseases and cancers. The success of these approaches is predicated on unraveling the complexity of immune recognition and pathways of activation. Nowhere would this knowledge be more prescient than for design of novel $\mathrm{T}$ cell-based vaccines (Bambini and Rappuoli, 2009). While the world's currently licensed vaccines against infectious pathogens almost exclusively target generation of antibody production, this strategy is 
efficient exclusively against those pathogens that are invariant or change little in amino acid sequence over time (i.e., diphtheria, tetanus, $\mathrm{H}$. influenza $\mathrm{B}$, polio, pneumococcus, meningococcus, etc.) Targeting of vaccine-induced antibodies to influenza $A$ hemagglutinin and neuraminidase which vary on an annual basis is a formidable task. Daily variation in HIV-1 evolution makes conventional vaccine approaches virtually impossible: the humoral immune system directed at highly variable sequences of the virus cannot keep pace with the evolving sequence changes.

Influenza A is a case in point. Influenza A is zoonotic (crosses species) and, especially in avian hosts, often enzootic (replicates without overt host damage). It is widely dispersed in waterfowl. The large reservoir of this highly variable virus and its potential for rapid transmission places a premium on developing vaccination methods that are inherently more stable to antigenic variation. This need has focused attention on $\mathrm{T}$ cell cellular immunity necessitating the identification of optimal MHCI-bound peptides expressed on virus-infected human lung epithelial cells and the induction of an effective CTL response mediated by these peptides. By "optimal" we mean the target peptides must be expressed on infected respiratory epithelium where productive viral replication occurs, are conserved among virtually all influenza A viruses and are restricted by HLA molecules that cover a broad range of ethnicities. Advances in bioinformatics and proteomics of HLA display can be used to achieve those key goals (Schirle et al., 2000; Lemmel et al., 2004; Weinzierl et al., 2007; Lin et al., 2008a,b; Reinhold et al., 2010). Elicitation of protective CTLs against critical influenza determinants in the lung offers the potential of creating a universal influenza vaccine to prophylax against both seasonal and pandemic strains of virus. Failure to naturally cross-present these optimal epitopes in the regional lymph nodes may favor expansion of $\mathrm{T}$ cells with poor protection, accounting for the perception that $\mathrm{T}$ cells are not useful in combating influenza infections. Mechanistic understanding of cognate immunity allows us to create new rules, however. In addition to influenza, such an approach has broad implications for $\mathrm{CD}^{+}$ $\mathrm{T}$ cell vaccines against other infectious agents, including Hepatitis $\mathrm{C}$ virus where it is already becoming clear that CD8 T cell immunity contributes in an important way to protection (Yu and Chiang, 2010).

Bioinformatics can provide platforms to address pathogen sequence diversity and human HLA diversity through targeting conserved viral sequences and identification of promiscuous binding peptides (affording population coverage to a large segment of the disease-susceptible population), respectively. As HLA is pivotal for functions of the immune system and determinant in antigen presentation, a systematic approach to $\mathrm{T}$ cell-based antigen design is required given that HLA is the most highly polymorphic of known human genes. Currently, there are more than 5,000 HLA alleles expressed by human beings on our planet (http://www.imgt.org). Within the United States alone, there are 3,112 HLA-ABC haplotypes with greater than 9,684,544 combinations. Computational methods that predict peptide binding to a majority of alleles within a supertype dramatically reduce the complexity of peptides required to afford population protection coverage (Reche and Reinherz, 2005; Zhang et al., 2010). These predictive methods will become more rapid and accurate in future years. Detection of the subset of predicted peptides actually displayed on infected cells or tumor cells by evolving mass spectrometry methods (Poisson detection $\mathrm{MS}^{3}$, $\mathrm{MS}^{\mathrm{E}}$, or $\mathrm{MS}^{\mathrm{N}}$ ) will allow for precise epitope targeting, obviating cross-presentation of epitopes not displayed on the pathologically dysfunctional cell or irrelevant crossreactivity resulting from reverse immunology methods (Reinhold et al., 2010).

Facile determination of complete HLA typing will assist in prediction of useful responses to vaccines among members of the population. In addition, transcriptome/ proteome approaches, multiplex assays, multiparameter phenotyping, and systems biology will assist with the understanding of how the human immune system's steady state is perturbed by infection or vaccination approaches. In short order, it should be possible to ascertain whether an individual response to a vaccine may afford protection or whether during the course of natural infection, the outcome will be favorable or unfavorable.

While details of cognate recognition are critical for vaccine design, this is but one part of the story. Determination of how to elicit high avidity $\mathrm{T}$ cells as effectors, memory, and effector/memory populations under the appropriate cytokine milieu followed by mobilization of these cells into the infected organ via relevant chemokines and addressins is necessary to induce the protective response. In addition, augmenting the relevant effector/effector memory population by concurrent blockade of inhibitory pathways (CTLA4, PD-1R, and A2AR) seems logical. That said, the details of pathway function and optimal kinetics of interdiction relative to antigen stimulation require elucidation. Finally, it is important to acknowledge that $\mathrm{T}$ cell biology needs to be considered in conjunction with that of B cells, immunologic memory, innate immunity, tolerance, and inflammation, all of which are addressed within Frontiers in Immunology.

\section{ACKNOWLEDGMENTS}

Oreste Acuto is supported by a Wellcome Trust Programme Grant no. GR076558MA and EU-FP7 "Sybilla” no. 201106. Ellis L. Reinherz is supported by NIH funding through NIAID.

\section{REFERENCES}

Acuto, O., Di Bartolo, V., and Michel, F. (2008). Tailoring T-cell receptor signals by proximal negative feedback mechanisms. Nat. Rev. Immunol. 8, 699-712.

Acuto, O., Fabbi, M., Smart, J., Poole, C. B., Protentis, J., Royer, H. D., Schlossman, S. F., and Reinherz, E. L. (1984). Purification and NH2-terminal amino acid sequencing of the beta subunit of a human T-cell antigen receptor. Proc. Natl. Acad. Sci. U.S.A. 81, 3851-3855.

Acuto, O., Hussey, R. E., Fitzgerald, K. A., Protentis, J. P., Meuer, S. C., Schlossman, S. F., and Reinherz, E. L. (1983a). The human T cell receptor: appearance in ontogeny and biochemical relationship of alpha and beta subunits on IL-2 dependent clones and T cell tumors. Cell 34, 717-726.

Acuto, O., Meuer, S. C., Hodgdon, J. C., Schlossman, S. F., and Reinherz, E. L. (1983b). Peptide variability exists within alpha and beta subunits of the T cell receptor for antigen. J. Exp. Med. 158, 1368-1373.

Allison, J. P., McIntyre, B. W., and Bloch, D. (1982). Tumor-specific antigen of murine T-lymphoma defined with monoclonal antibody. J. Immunol. 174, 1144-1151.

Arnett, K. L., Harrison, S. C., and Wiley, D. C. (2004). Crystal structure of a human CD3-epsilon/delta dimer in complex with a UCHT1 single-chain antibody fragment. Proc. Natl. Acad. Sci. U.S.A. 101, 16268-16273.

Baker, P.E., Gillis, S., and Smith, K.A. (1979). Monoclonal cytolytic T-cell lines. J. Exp. Med. 149, 273-278.

Bambini, S., and Rappuoli, R. (2009). The use of genomics in microbial vaccine development. Drug Discov. Today 14, 252-260. 
Bjorkman, P. J., Saper, M. A., Samraoui, B., Bennett, W. S., Strominger, J. L., and Wiley, D. C. (1987). The foreign antigen binding site and $\mathrm{T}$ cell recognition regions of class I histocompatibility antigens. Nature 329, 512-518.

Brockmeyer,C.,Paster,W.,Pepper,D., Tan,C.P., Trudgian,D. C., McGowan, S., Fu, G., Gascoigne, N.R.,Acuto, O., and Salek,M.(2010). T cell receptor (TCR)-induced tyrosine phosphorylation dynamics identifies themis as a new TCR signalosome component. J. Biol. Chem. Available at: http://www.jbc.org/content/early/2010/12/28/jbc. M110.201236.full.pdf + html? sid=a80b0c8c-898a4529-885f-dbd2930a9fb5

Call, M.E., Schnell, J.R., Xu, C., Lutz, R. A., Chou, J. J., and Wucherpfennig, K.W.(2006). The structure of the $\zeta \zeta$ transmembrane dimer reveals features essential for its assembly with the T cell receptor. Cell 127, 355-368.

Clevers, H., Alarcon, B., Wileman, T., and Terhorst, C. (1988). The T cell receptor/CD3 complex: a dynamic protein ensemble. Annu. Rev. Immunol. 6, 629-662.

Debre, P., and Forster,E. (1998).In Louis Pasteur. Baltimore: Johns Hopkins University Press, 148-176.

Dustin, M. L., Chakraborty, A. K., and Shaw, A. S. (2010). Understanding the structure and function of the immunological synapse. Cold Spring Harb. Perspect. Biol. 2, a002311.

Fernandez, E. J., and Lolis, E. (2002). Structure, function, and inhibition of chemokines. Annu. Rev. Pharmacol. Toxicol. 42, 469-499.

Fu, G., Vallee, S., Rybakin, V., McGuire, M. V., Ampudia, J., Brockmeyer, C., Salek, M., Fallen, P. R., Hoerter, J. A., Munshi, A., Huang, Y. H., Hu, J., Fox, H. S., Sauer, K., Acuto, O., and Gascoigne, N. R. (2009). Themis controls thymocyte selection through regulation of T cell antigen receptor-mediated signaling. Nat. Immunol. 10, 848-856.

Haskins, K., Kubo, R., White, J., Pigeon, M., Kappler, J., and Marrack, P. (1983). The major histocompatibility complex-restricted antigen receptor on T cells. I. Isolation with a monoclonal antibody. J. Exp. Med. 157, 1149-1169.

Hedrick, S. M., Cohen, D. I., Nielsen, E. A., and Davis, M. M. (1984a). Isolation of cDNA clones encoding T cell-specific membrane-associated proteins. Nature 308, 149-153.

Hedrick, S. M., Nielsen, E. A., Kavaler, J., Cohen, D. I., and Davis, M. M. (1984b). Sequence relationships between putative T-cell receptor polypeptides and immunoglobulins. Nature 308, 153-158.

Hynes, R. O. (2002). Integrins: bidirectional, allosteric signaling machines. Cell 110, 673-687.

Irving, B. A., and Weiss, A. (1991). The cytoplasmic domain of the $\mathrm{T}$ cell receptor $\zeta$ chain is sufficient to couple to receptor-associated signal transduction pathways. Cell 64, 891-901.

Jardetzky, T. S., Brown, J. H., Gorga, J. C., Stern, L. J., Urban, R. G., Chi, Y. I., Stauffacher, C., Strominger, J. L., and Wiley, D. C. (1994). Three-dimensional structure of a human class II histocompatibility molecule complexed with superantigen. Nature 711-718.

Johnson, A. L., Aravind, L., Shulzhenko, N., Morgun, A., Choi, S. Y., Crockford, T. L., Lambe, T., Domaschenz, H., Kucharska, E. M., Zheng, L., Vinuesa, C. G., Lenardo, M. J., Goodnow, C. C., Cornall, R. J., and Schwartz, R. H. (2009). Themis is a member of a new metazoan gene family and is required for the completion of thymocyte positive selection. Nat. Immunol. 10, 831-839.
Julius, M. H., Masuda, T., and Herzenberg, L. A. (1972). Demonstration that antigen-binding cells are precursors of antibody-producing cells after purification with a fluorescence-activated cell sorter. Proc. Natl. Acad. Sci. U.S.A. 69, 1934-1938.

Kappler, J., Kubo, R., Haskins, K., Hannum, C., Marrack, P., Pigeon, M., McIntyre, B., Allison, J., and Trowbridge, I. (1983). The major histocompatibility complexrestricted antigen receptor on $\mathrm{T}$ cells in mouse and man: identification of constant and variable peptides. Cell 35, 295-302.

Kim, S. T., Takeuchi, K., Sun, Z. Y., Touma, M., Castro, C. E., Fahmy, A., Lang, M. J., Wagner, G., and Reinherz, E. L. (2009). The alphabeta T cell receptor is an anisotropic mechanosensor. J. Biol. Chem. 284, 31028-31037.

Kjer-Nielsen, L., Dunstone, M. A., Kostenko, L., Ely, L. K., Beddoe, T., Mifsud, N. A., Purcell, A. W., Brooks, A. G., McCluskey, J., and Rossjohn, J. (2004). Crystal structure of the human T cell receptor CD3E $\gamma$ heterodimer complexed to the therapeutic mAb OKT3. Proc. Natl. Acad. Sci. U.S.A. 101, 7675-7680.

Lemmel, C., Weik, S., Eberle, U., Dengjel, J., Kratt, T. Becker, H. D., Rammensee, H. G., and Stevanovic, S. (2004). Differential quantitative analysis of MHC ligands by mass spectrometry using stable isotope labeling. Nat. Biotechnol. 22, 450-454.

Lesourne, R., Uehara, S., Lee, J., Song, K. D., Li, L. Pinkhasov, J., Zhang, Y., Weng, N. P., Wildt, K. F., Wang, L., Bosselut, R., and Love, P.E. (2009). Themis, a T cell-specific protein important for late thymocyte development. Nat. Immunol. 10, 840-847.

Letourneur, F., and Klausner, R. D. (1992). Activation of $\mathrm{T}$ cells by a tyrosine kinase activation domain in the cytoplasmic tail of CD3E. Science 255, 79-82.

Lin, H. H., Ray, S., Tongchusak, S., Reinherz, E. L., and Brusic, V. (2008a). Evaluation of MHC class I peptide binding prediction servers: applications for vaccine research. BMC Immunol. 9, 8. doi: 10.1186/14712172-9-8

Lin, H. H., Zhang, G., Tongchusak, S., Reinherz, E. L., and Brusic, V. (2008b). Evaluation of MHC-II peptide binding prediction servers: applications for vaccine research. BMC Bioinformatics 9(Suppl. 12), S22. doi: 10.1186/1471-2105-9-S12-S22

Luber, C. A., Cox, J., Lauterbach, H., Fancke, B., Selbach, M., Tschopp, J., Akira, S., Wiegand, M., Hochrein, H., O'Keeffe, M., and Mann, M. (2009). Quantitative proteomics reveals subset-specific viral recognition in dendritic cells. Immunity 32, 279-289.

Mayya, V., Lundgren, D. H., Hwang, S. I., Rezaul, K., Wu, L., Eng, J. K., Rodionov, V., and Han, D. K. (2009). Quantitative phosphoproteomic analysis of T cell receptor signaling reveals system-wide modulation of protein-protein interactions. Sci. Signal. 2, ra46.

Meuer, S. C., Acuto, O., Hussey, R. E., Hodgdon, J. C., Fitzgerald, K. A., Schlossman, S. F., and Reinherz, E. L. (1983a). Evidence for the T3-associated 90K heterodimer as the T-cell antigen receptor. Nature 303, 808-810.

Meuer, S. C., Fitzgerald, K. A., Hussey, R. E., Hodgdon, J. C., Schlossman, S. F., and Reinherz, E. L. (1983b). Clonotypic structures involved in antigen-specific human T cell function. Relationship to the T3 molecular complex. J. Exp. Med. 157, 705-719.

Meuer, S. C., Schlossman, S. F., and Reinherz, E. L. (1982). Clonal analysis of human cytotoxic T lymphocytes: $\mathrm{T} 4+$ and $\mathrm{T} 8+$ effector $\mathrm{T}$ cells recognize products of different major histocompatibility complex regions. Proc. Natl. Acad. Sci. U.S.A. 79, 4395-4399.

Milstein, C. (1993). "From the structure of antibodies to the diversification of the immune response," in Nobel Lectures, Physiology or Medicine 1981-1990, eds T. Frängsmyr and J. Lindsten (Singapore: World Scientific Publishing), 248-270.

Murphy, K. M., Travers, P., and Walport, M. (2007). Janeway's Immunobiology. New York: Garland Science.

Nika, K., Soldani, C., Salek, M., Paster, W., Gray, A., Etzensperger, R., Fugger, L., Polzella, P., Cerundolo, V., Dushek, O., Höfer, T., Viola, A., and Acuto, O. (2010). Constitutively active Lck kinase in T cells drives antigen receptor signal transduction. Immunity 32, 766-777.

Reche, P. A., and Reinherz, E. L. (2005). PEPVAC: a web server for multi-epitope vaccine development based on the prediction of supertypic MHCligands. Nucleic Acids Res. 33, W138-W142.

Reinherz, E. L., Meuer, S., Fitzgerald, K. A., Hussey, R. E., Levine, H., and Schlossman, S. F. (1982). Antigen recognition by human $\mathrm{T}$ lymphocytes is linked to surface expression of the T3 molecular complex. Cell 30, 735-743.

Reinhold, B., Keskin, D. B., and Reinherz, E. L. (2010). Molecular detection of targeted major histocompatibility complex I-bound peptides using a probabilistic measure and nanospray MS(3) on a hybrid quadrupole-linear ion trap. Anal. Chem. 82, 9090-9099.

Reth, M. (1989). Antigen receptor tail clue. Nature 338, 383-384.

Rudd, C. E., Taylor, A., and Schneider, H. (2009). CD28 and CTLA- 4 coreceptor expression and signal transduction. Immunol. Rev. 229, 12-26.

Rudolph, M. G., Stanfield, R. L., and Wilson, I. A. (2006). How TCRs bind MHCs, peptides, and coreceptors. Annu. Rev. Immunol. 24, 419-466.

Schirle, M., Keilholz, W., Weber, B., Gouttefangeas, C., Dumrese, T., Becker, H., Stevanovic, S., and Rammensee, H. G. (2000). Identification of tumor-associated MHC class I ligands by a novel T cell-independent approach. Eur. J. Immunol. 30, 2216-2225.

Sitkovsky, M. V. (2009). T regulatory cells: hypoxiaadenosinergic suppression and re-direction of the immune response. Trends Immunol. 30, 102-108.

Sun, Z.-Y. J., Kim, K. S., Wagner, G., and Reinherz, E. L. (2001). Mechanisms contributing to T cell receptor signaling and assembly revealed by the solution

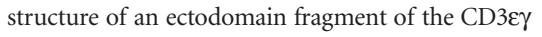
heterodimer. Cell 105, 913-923.

Sun, Z.-Y. J., Kim, S. T., Kim, I. C., Fahmy, A., Reinherz, E. L., and Wagner, G. (2004). Solution structure of the CD3 ectodomain and comparison with CD3 as a basis for modeling $\mathrm{T}$ cell receptor topology and signaling. Proc. Natl. Acad. Sci. U.S.A. 101, 16867-16872.

Tonegawa, S. (1993). "Somatic generation of immune diversity," in Nobel Lectures: Physiology or Medicine 1981-1990, eds T. Frångsmyr and J. Lindsten (Singapore: World Scientific Publishing), 381-405.

Unanue, E. R. (2006). From antigen processing to peptideMHC binding. Nat. Immunol. 7, 1277-1279.

Wang, J.-H., and Reinherz, E. L. (2002). Structural basis of T cell recognition of peptides bound to $\mathrm{MHC} \mathrm{mol-}$ ecules. Mol. Immunol. 38, 1039-1049. 
Weinzierl, A. O., Lemmel, C., Schoor, O., Müller, M., Krüger, T., Wernet, D., Hennenlotter, J., Stenzl, A., Klingel, K., Rammensee, H. G., and Stevanovic, S. (2007). Distorted relation between mRNA copy number and corresponding major histocompatibility complex ligand density on the cell surface. Mol. Cell Proteomics 6, 102-113.

Weiss, A. (2009). TCR signal transduction: opening the black box. J. Immunol. 183, 4821-4827.

Yanagi, Y., Yoshikai, Y., Leggett, K., Clark, S. P., Aleksander, I., and Mak, T. W. (1984). A human T cell-specific cDNA clone encodes a protein having extensive homology to immunoglobulin chains. Nature 308, 145-149.
Yu, C. I., and Chiang, B. L. (2010). A new insight into hepatitis $\mathrm{C}$ vaccine development. J. Biomed. Biotechnol. 2010, 548280.

Zhang, G. L., Deluca, D. S., Keskin, D. B., Chitkushev, L., Zlateva, T., Lund, O., Reinherz, E. L., and Brusic, V. (2010). MULTIPRED2: a computational system for large-scale identification of peptides predicted to bind to HLA supertypes and alleles. J. Immunol. Methods doi: 10.1016/j.jim.2010.11.009. [Epub ahead of print].

Zinkernagel, R. M. (1997). The nobel lectures in immunology. The Nobel prize for physiology or medicine, 1996: cellular immune recognition and the biological role of major transplantation antigens. Scand. J. Immunol. 46, 421-436.
Received: 24 January 2011; accepted: 25 January 2011; published online: 07 February 2011.

Citation: Reinherz EL and Acuto O (2011) Molecular $T$ cell biology - basic and translational challenges in the twenty-first century. Front. Immun. 2:3. doi: 10.3389/ fimmu.2011.00003

This article was submitted to Frontiers in T Cell Biology, a specialty of Frontiers in Immunology.

Copyright (c) 2011 Reinherz and Acuto. This is an openaccess article subject to an exclusive license agreement between the authors and Frontiers Media SA, which permits unrestricted use, distribution, and reproduction in any medium, provided the original authors and source are credited. 